\title{
CrossQuestion Game: A Group-Based Assessment for Gamified Flipped Classroom Experience Using the ARCS Model
}

\author{
Usman Durrani \\ Department of Computer Science, School of Systems and Technology, University of Management and \\ Technology, Pakistan \\ ORCID: 0000-0003-4255-6253 \\ Omar Hujran \\ Department of Analytics in the Digital Era, College of Business and Economics, United Arab Emirates \\ University, United Arab Emirates \\ ORCID: 0000-0002-0334-3354
}

Ahmad Samed Al-Adwan

Department of Electronic Business and Commerce, Business School, Al-Ahliyya Amman University, Amman, Jordan

ORCID: 0000-0001-5688-1503

\begin{abstract}
The importance of formal online education has been felt like never before because of the ongoing nature of the COVID-19 pandemic. Researchers and academics are continuously experimenting with combinations of established pedagogies, tools, and technologies to enhance or sustain the student learning process and motivation. For this study, we have designed and developed a multi-player game called CrossQuestion to explore the combined effect of applying gamification and flipped classroom pedagogies using the ARCS (Attention, Relevance, Confidence, and Satisfaction) model guidelines and its application in the obligatory IT foundation online course during the pandemic. We delivered this course to 79 undergraduate (mostly) non-IT students in Ajman University, UAE. Students were randomly divided into a non-gamified cohort (35 students gone through lecture-based instructions and paper-based assessments-Spring 2019-20-pre-COVID-19 face to face environment) and a gamified flipped classroom cohort (44 students, played the CrossQuestion game-Spring 2020-21-during COVID-19 online environment). We collected the survey data anonymously through our customized Instructional Materials Motivation Survey (IMMS) tool and then performed descriptive analysis, t-test, and regression analysis to address the research hypothesis. We found a significant relationship between learning motivational factors and learning effectiveness. We also found the positive influence of our game on students' motivation.
\end{abstract}

Keywords: flipped classroom, gamification, motivation, ARCS motivation model, instructional materials motivation survey (IMMS), educational game

\section{INTRODUCTION}

In January 2020, education around the world has seen multi-facet challenges due to COVID-19 (Pavlíková et al., 2021). With daily lockdowns from March 2020, the education environment of many UAE universities became less operational to deliver their well-established programs due to the traditional face-to-face 
delivery models. More importantly, a need for a solution to sustain students' motivation and engagement them in the learning process (Al-Adwan et al., 2021; Tkáčová et al., 2021). For us, a bigger challenge was the delivery of technical courses to students with a non-technical background in a digital synchronous environment. Students in these circumstances often find themselves overloaded and stranded.

Gamification and flipped classroom pedagogies in the right combination can help especially in such online environments, making the delivery process more pleasant, expressive, relevant, and appealing, and as a result improve the outcomes of their studies (Deterding et al., 2011; McLaughlin et al., 2014). According to Deterding et al. (2011), "gamification" is the use of game design elements in non-game contexts. Whereas "flipped classroom" is an educational technique that consists of two parts: interactive group learning activities inside the classroom and direct computer-based individual instruction outside the classroom (Bishop \& Verleger, 2013). We have applied this combination of gamification, flipped classroom pedagogies, to explore its effectiveness through our group-centered assessment game, the "CrossQuestion" for an online classroom environment during the COVID-19 pandemic. We enrolled students from multiple colleges in an Information Technology in Business course at Ajman University. The course covered basic IT topics such as introduction to IS and IT, e-business, ethical issues, e-commerce, security, telecommunication infrastructure, and global management.

While flipped classrooms in higher education can be recognized as an effective approach, there is a lack of research to sufficiently address how in-class activities in an online environment should be designed to be effective for learning (Sailer \& Sailer, 2021). In addition, most of these studies have not applied game design elements to in-class activities except Yildirim (2017) who examined the effects of gamified-learning practices on out-and in-class activities. Further, it has been argued that gamification is an effective tool to improve learning and motivation. However, the effects of gamification vary depending on the different elements of game design. Subhash and Cudeny (2018) state that previous research has reported several benefits of gamification to motivation and learning, but the results regarding the performance of students were inconsistent and inconclusive.

The motivation to develop the CrossQuestion game was to promote a group-oriented online environment where students take part in a team to prepare for a gamified flipped classroom session, and to engage with other student teams through in-classroom activities, resulting in enhancing the overall learning process during the COVID-19 pandemic. This paper describes the implementation and evaluation of the CrossQuestion educational game designed and developed to motivate students using an experimental study method in the spring semesters 2020-21.

Through this research we are hoping to contribute to the emerging body of literature on the ARCS model, processes, and practices and its application through custom-designed educational games. We will demonstrate through our group-oriented game the integration of ARCS model practices and its application through CrossQuestion to enhance or sustain student motivation and learning effectiveness. The experience gained from this research will enable us to enhance our game further in alignment with gamified and flipped classroom pedagogies and to extend its application to other academic programs such as medical, architecture, engineering, and professional training.

This paper is structured, as follows. In the next section, we will provide the literature review relevant to the pedagogies, groups-oriented assessments, and the motivational model, the ARCS. We will then describe the "CrossQuestion" game. After that we will explain our research methodology and the application of our game through gamified flipped classroom combination in "Information Technology in Business" course. We provide research findings and discussion. We finally conclude with implications, limitations, and future studies.

\section{LITERATURE REVIEW AND HYPOTHESIS DEVELOPMENT}

Keeping high motivation of students even with high quality of online education is one of the key challenges. From this perspective, gamification is seen as one solution to motivate and evaluate the user's engagement with the system (Jang et al., 2015). Researchers have shown the importance of game-based learning and its 
positive effect on education (Hwang et al., 2015). In their systematic analysis, Krause et al. (2015) studied the impact of social gamification on student retention and learning success in online courses. Social gamification is a subset of the wider concept of gamification where the elements from social games are used in nongame applications (Simões et al., 2013). Krause et al. (2015) research concluded with strong support for the hypothesis that gamification can increase retention and that social gamification amplifies this effect. The creativity of the teacher to integrate gamification in the course delivery design along with the students' ability to survive or excel in a gaming environment can lead to improved grades, which as a result can improve the satisfaction of the students in their course, and program overall (Kaufmann, 2018). Juan and Chao (2015) show that using a game in learning increases learning effectiveness and provides strong learning motivation. Their finding implies that learners can achieve a high level of satisfaction during the game process.

The recent emergence of flipped classroom delivery approach in a teaching environment contributed to boosting students' participation and more active learning in higher education (McLaughlin et al., 2016). This approach is a pre-lecture self-learning while referring to the delivery of lecture resources to students before class, while the in-class activities are in the format of group discussions, exercises, or projects (Milman, 2012). Many studies (Goh \& Ong, 2019; McCarthy, 2016; Nouri, 2016) based on their empirical studies have identified the usefulness of flipped classroom approaches in cultivating student academic accomplishment and performance comparing to traditional methods. Jensen et al. (2018) have further investigated different innovative technologies and strategies that can make flipped classroom approach more effective.

It is believed that integrating gamification and flipped classroom strategies can be an effective learning approach to the students' learning achievement and their motivation (Asiksoy, 2017; Zainuddin, 2018). By adding a ranking system into the online lecture system through flipped classrooms can increase competitive spirit and interest in online preparation before class (Jo et al., 2018). In a different study, it was suggested that peer interactions inside the flipped classroom were critical to promoting students' achievement and cognitive engagement, as opposed to online learning resources and gamification (Lo \& Hew, 2020). Another research attempted to prepare the guidelines and identify the benefits of five nontraditional teaching methods such as flipped classroom, gamification, case study, self-learning, and social media (Safapour et al., 2019). They concluded that implementing the flipped classroom, gamification, and self-learning methods improves students' intrinsic motivation and that the adoption of the social media method changes into lifelong learning and promotes creativity (Safapour et al., 2019).

Universities are now encouraging more group-based and peer-based assessments to facilitate learning and enhance academic knowledge (Heathfield, 1999). Group-based assessments through peer interaction are becoming an increasingly popular approach for assessing the understanding of students in a context different subject (Heathfield, 1999). Joo (2017) explored different factors to the individual's contributions in group work. These factors included gender, age, academic year, and group work preference. The result of the study showed that the only factor that influenced group work contribution is the existence of an individual assessment method. The result of another study suggested that repeated exposure to cooperative learning had benefits, in terms of social benefits, peer learning, and transferable skills (Healy et al., 2018). The result of Chiriac (2014) showed that most of the students gain experience while working in a group, facilitated learning, academic knowledge, and collaborative abilities. The importance of incorporating group-based assessments comes from the fact that learning itself is inherently a social activity. The primary aim of using group-based assessment is to develop the students' teamwork and communication skills (Heathfield, 1999).

Overall, it requires a combination of many approaches to ensure that group work is assessed effectively and to reflect on the work completed by the student group and the individual contribution within it (Clarke \& Blissenden, 2013). Selecting the right approaches to implement these types of group assessments can be challenging. Therefore, a need to train academics to promote a collaborative learning environment, where the students are encouraged to work with each other (Mbalamula, 2018). It is also crucial to incorporate tools and technologies that permit the students to collaborate and communicate easily with each other (Gamlath \& Wilson, 2017). 
For this study, we have applied the ARCS (Attention, Relevance, Confidence, and Satisfaction) instructional model guidelines by Keller (2010) along with flipped classroom and gamification pedagogies to design, develop, and used our CrossQuestion multiplayer game to focus on students' motivation in an online environment during COVID-19 pandemic. ARCS model's application can support enhance and/or maintain the students' learning motivation in an online environment (Li \& Keller, 2018; Malik, 2014; Milman \& Wessmiller, 2016). This model is important for e-learning, since motivating learners in an online course is more difficult than in face-to-face courses (Chyung, 2001). Attention refers to the learners' interest, where teaching resources used can attract and maintain learners' interest and attention. Relevance refers to the clarity of course design that must show the usefulness of the instructional resources so that students can connect the course content with the real world. Confidence focuses on increasing the success expectations among learners and thus increasing confidence and motivation. Satisfaction is a direct relationship between motivation and satisfaction. Satisfied learners can achieve more in their learning process.

To evaluate if our CrossQuestion multi-player game using a gamified-flipped classroom approach under the guideline of ARCS instructional model in an online environment during the COVID-19 pandemic added any positive value, two hypotheses were identified.

H1: Gamified-flipped classroom online delivery using CrossQuestion group-based games have a positive influence on students' grades during COVID-19.

H2: Gamified-flipped classroom online delivery using CrossQuestion group-based games have a positive influence on students' motivation during COVID-19.

\section{CROSSQUESTION GAME DESIGN}

The inspiration behind designing and developing the CrossQuestion multi-player game is to boost a grouporiented atmosphere for students to take part in a team to prepare for a flipped classroom online session, and to engage with other student teams through in-classroom activities, resulting in enhancing the overall learning process. During the game, the key aim of all teams is to protect their 100 points while taking away points from other competing teams. This is done by asking and responding to the questions of competing teams in a gamified environment.

Some prerequisites to play our game in a gamified flipped classroom environment includes:

- Sufficient time was provided to the teams to prepare.

- Relevant and consistent material or resources provided to the teams.

Additional ground rules included:

- Teams can choose to have three to six students either self-nominated or assigned by the teachers.

- Teams with the late submission are disqualified from the competition.

- All submitted questions are reviews by the teacher before the competition. However, teams are not informed of any rejected question(s), and the opponent teams are awarded points during the surprise stage.

- All teams identify 10 questions - 4 challenge-questions of five points each, 4 challenge questions of ten points each, and 2 challenge questions of twenty points each.

- The game starts with 100 points for each team (see Figure 1).

A further description of the GUI interface (Figure 2) and sequence of stages (Figure $\mathbf{3}$ ) is presented in Table 1. 


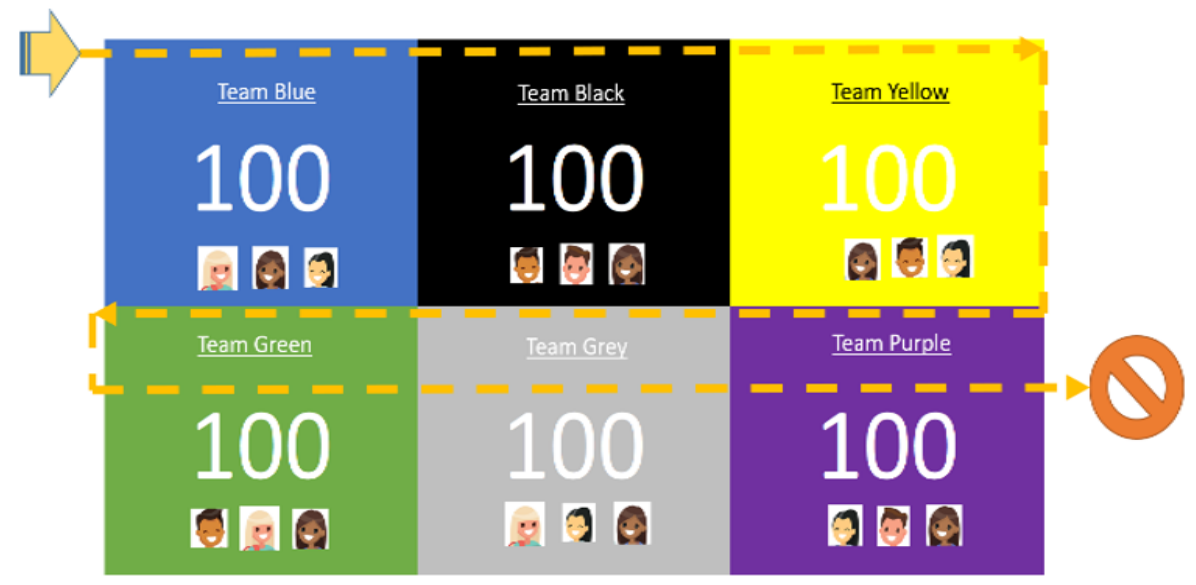

Figure 1. Starting stage of CrossQuestion game
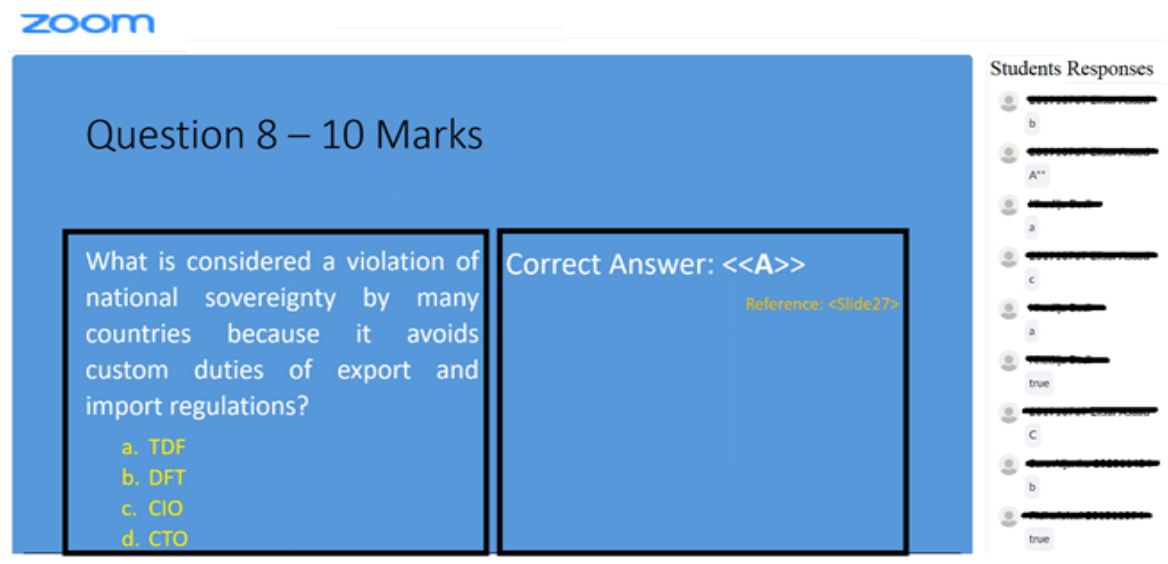

Figure 2. Response stage of CrossQuestion game

\section{RESEARCH METHODOLOGY}

The key objectives of this research study were: 1 ) to evaluate the influence of the CrossQuestion game on student grades and learning motivation of gamified-flipped classroom cohort (Spring 2020-21/during COVID19 online environment) aligned with ARCS model guidelines and 2) to cross-validate the learning effectiveness and its relationship with the four aspects of the ARCS model: attention, relevance confidence, and satisfaction. The teacher first delivered the course to the non-gamified cohort of thirty-five students (Spring 2019-20/pre-COVID-19) in a face-to-face environment with two lectures of one and a half hours each per week ending with a $Q$ \& A session. The assessments included two paper-based quizzes, a team project, lab assessments, a paper-based midterm, and a paper-based final exam. The course explored various IT basic topics, including an introduction to e-commerce, e-business, security, telecommunication infrastructure, global management through IT, and ethical issues.

The same course and material were then delivered to forty-four gamified flipped classroom cohorts in Spring 2020-21/during the COVID-19 online environment. No additional material was used that was not available to the non-gamified cohort. The delivery format for the experimental (gamified-flipped-classroom) cohort included a presentation session of one and half hours and one activity session of one and half hours a week. During the presentation session, the lecturer runs through the main points to cover in the material, and then a detailed reading of the resources was performed by the students after the class in preparation for an activity day. On the activity day, the lecturer used the CrossQuestion application incorporating all the questions provided by the students in advance. These activities were an add-on to the main course assessments. 


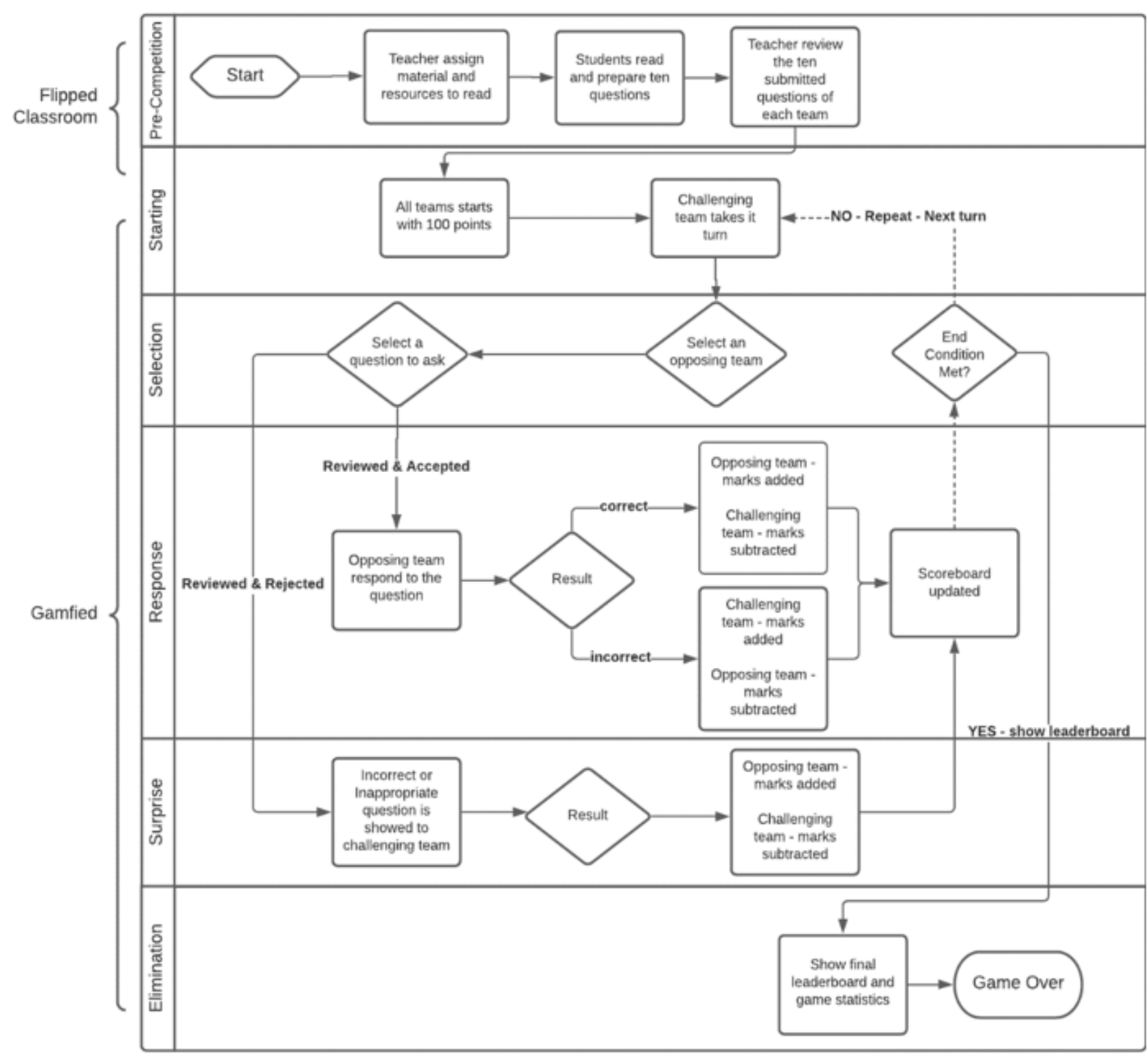

Figure 3. Flow diagram of CrossQuestion game

Table 1. CrossQuestion game stages

Game stage Stage description

Pre- $\quad$ All the prerequisites of the game must be met.

competition Also, students have a clear understanding of the ground rules of the game.

stage

Opening Each team starts with 100 points and 10 submitted and approved questions.

stage Students are allowed to refer to all the resources including their short notes, lecture slides, text or reference books, and even the internet during the competition.

Students' teams during their turn can enable mics (via any communication tool used) to communicate with each other, but only one nominated member is allowed to take the final decision to select the opposing team and the question to ask.

Choice The first team in sequence takes its turn and chooses an opponent team and a challenging question to stage ask.

A selected question can be of any point weightage as first-team think appropriate, This two-step selection (opposing team and then question to ask) is required to be completed within ten seconds in each turn. 
Table 1 (Continued).

Game stage Stage description

Response The opponent team members can communicate and consult with each other verbally during their turn, stage but only one nominated team member is allowed to type in the final answer in the chatbox of the communication tool used (Figure 2).

If the opponent team answers the question successfully within 25 seconds of their allocated time, the game automatically adds question reward points to the opponent team's total score. Same points are deducted from the challenging team's total score.

Else challenging team wins the points and the opponent team loses the same amount of points Choice stage and response stage are repetitive and continues until the game meets the ending stage conditions (Figure 3).

Surprise During the competition, if a challenging team is going to pick up a question pre-reviewed and rejected by stage the teacher (because, it was vague, or incorrect, or two long for 25 seconds MCQ, or mistakes in the question or multiple options, or not from the material or resources provided, etc.), question points are automatically awarded to the selected opposing team.

The reason(s) for rejection is also shown to the challenging team so that it is not repeated in future competitions.

Completion A team with below 50 points is wiped out from the competition, immediately or, if teams have used all stage their questions arsenal or, the lecture time is over.

The team with the highest score emerges as a winning team. Encouragement points can also be provided to runners-up.

Table 2. Characteristics of cohorts

\begin{tabular}{|c|c|c|}
\hline $\begin{array}{l}\text { Research } \\
\text { perspectives }\end{array}$ & $\begin{array}{l}\text { Non-gamified } \\
\text { Spring 2019-20 (pre-COVID-19 face to face } \\
\text { environment) }\end{array}$ & $\begin{array}{l}\text { Gamified flipped classroom } \\
\text { Spring 2020-21 (during COVID-19 online } \\
\text { environment) }\end{array}$ \\
\hline $\begin{array}{l}\text { Students' cohorts } \\
\text { and sample size }\end{array}$ & $\begin{array}{l}35 \text { students from IT/IS, Accounting, Finance, } \\
\text { Marketing, and Management }\end{array}$ & $\begin{array}{l}44 \text { students from IT/IS, Accounting, Finance, } \\
\text { Marketing, and Management }\end{array}$ \\
\hline $\begin{array}{l}\text { Duration of } \\
\text { course }\end{array}$ & $\begin{array}{l}15 \text { weeks (two lectures of one and half hours } \\
\text { each per week) }\end{array}$ & $\begin{array}{l}15 \text { weeks (one lecture session of one and half } \\
\text { hours and one activity session of one and half } \\
\text { hours per week) }\end{array}$ \\
\hline Credit hours & 3 credit hours & 3 credit hours \\
\hline Types of & One paper-based midterm exam (20\%) & One online midterm exam (30\%) \\
\hline assessments and & Two paper-based formal quizzes (20\%) & Two formal online quizzes (20\%) \\
\hline \multirow[t]{3}{*}{ weightage } & A team project $(20 \%)$ & A team project $(10 \%)$ \\
\hline & One paper-based final exam (30\%) & One online final exam (40\%) \\
\hline & Practical lab assessment (10\%) & $\begin{array}{l}\text { Five supplement CrossQuestion gamified online } \\
\text { quizzes and in classroom activities (5\%) }\end{array}$ \\
\hline
\end{tabular}

The characteristics of the cohorts are given in Table 2. The first four types of assessments used in both cohorts were the same but with the difference of either using paper-based or online formats. Assessment type 5 was different in both cohorts. The quizzes, mid and final-term exam assessments for both cohorts included MCQ, short essays, and scenario-based questions. Gamified online quizzes only included MCQ questions which can be responded to within 25 seconds as per game rules.

After the approval provided by the Ajman University ethics committee (approval\# MC-H-F-2020-04-30), we customized and launched our anonymous Instructional Materials Motivation Survey (IMMS) (Loorbach et al., 2015) in alignment with Keller's (2010) ARCS motivational model guidelines to determine if a particular delivery approach has increased or sustained the student's motivation to learn. This survey tool has been applied to the educational context multiple times to analyze learning motivational levels in a specific course or program context (Green \& Sulbaran, 2006; Rodgers \& Withrow-Thorton, 2005). For the result to be reliable using the IMMS tool, a Cronbach's alpha between 0.81 to 0.96 is recommended (Keller., 2009). The original IMMS uses 36 questions answered on a 5-point Likert scale to measure the motivational responses of students ( $1=$ Strongly disagree, 2=Disagree, 3=Neutral, 4=Agree, and 5=Strongly agree). For the non-gamified cohort, a paper-based questionnaire was used to collect responses from students. On the other hand, a web- 
Table 3. Descriptive statistics for IT in Business final grades

\begin{tabular}{lcc}
\hline & Non-gamified & Gamified flipped classroom \\
\hline Mean & Pre-COVID-19/Spring2019-2020 & During-COVID-19/Spring2020-21 \\
Standard deviation (SD) & 67.7 & 79.4 \\
Median & 6.8 & 8.6 \\
IQ range & 67 & 77 \\
\hline
\end{tabular}

Table 4. Results of regression analysis

\begin{tabular}{|c|c|c|c|}
\hline Dependent variable & Independent variable & $\mathrm{R}^{2}$ & $p$-value \\
\hline \multirow{4}{*}{$\begin{array}{l}\text { Learning effectiveness } \\
\text { (exam results) }\end{array}$} & Confidence & 0.675 & 0.000 \\
\hline & Attention & 0.401 & 0.000 \\
\hline & Relevance & 0.373 & 0.000 \\
\hline & Satisfaction & 0.331 & 0.000 \\
\hline
\end{tabular}

based questionnaire was employed to collect data from the gamified cohort. The web-based questionnaire was deemed an effective way to collect data especially in light of the social distancing imposed by the pandemic.

We collected the grades of the registered students in the course for pre-COVID-19/Spring 2019-20 and During-COVID-19/Spring 2020-21 semesters and performed their comparison, to test the $\mathbf{H} \mathbf{1}$. The lecturer and the course resources remained constant for both cohorts.

We presented both cohorts with the IMMS questionnaire using 36 questions (with slight customization) during PRE and POST the course delivery to test the H2 (Durrani et al., 2021). These 36 questions were grouped into four categories: Attention (ATTEN), Relevance (RELE), Confidence (CONF), and Satisfaction (SAT).

\section{RESEARCH FINDINGS}

We performed a t-test to compare the final grades of the pre-COVID-19/Spring 2019-20 non-gamified cohort with the final grades of the during COVID-19/Spring 2020-21 gamified-flipped classroom cohort. Before proceeding to the t-test, it was important to ensure that assumptions for the t-test are met. Accordingly, a normality test was performed by the Shapiro-Wilk W test for the two groups. The results indicate that both groups are normally distributed with a statistic of 0.952 and a p-value of 0.126 for the non-gamified cohort, and a statistic of 0.958 and a p-value of 0.112 for the gamified-flipped cohort. Based on the normality tests, performing a group comparison using t-test (unpaired two-tailed) was eligible.

The t-test results demonstrate that there was a significant difference in the scores for the gamified-flipped classroom cohort $(M=79.4, S D=8.6)$ and non-gamified cohort $(M=67.7, S D=6.8) ; t(77)=6.58$. $p$-value $<0.0001$. Such a result indicates that grades of gamified-flipped cohort students were significantly higher than nongamified cohort students (Table 3).

Regression analysis was used to cross-validate the results of the gamified flipped classroom cohort. The regression analysis aims to establish a relationship between learning effectiveness and motivation (decomposed into attention, relevance, confidence, and satisfaction). As presented in Table 4, there is a significant relationship between learning motivational factors and learning effectiveness as all $p$-values were less than $0.0001(p<0.05)$. Such positive correlation is consistent with results of previous literature (Juan \& Chao, 2015; Keller, 2010) and shows that if the delivered teaching models and instructional materials are attractive and address students' needs, it enables students to get a feeling of satisfaction and achievement with the learning process.

To test H2, we received 79 responses, which included 35 for the first survey (non-gamified cohort) and 44 for the second survey (gamified-flipped cohort). An internal consistency check was performed using Cronbach's alpha. For the non-gamified cohort survey, the value of Cronbach alpha was $0.86(\alpha=.86)$, and $0.92(\alpha=.92)$ 
for the gamified-flipped classroom cohort survey. Furthermore, a confirmatory factor analysis (CFA) was performed for the two datasets. the CFA revealed that four factors were extracted for each dataset (nongamified cohort survey and gamified cohort survey) as these factors in each dataset had an eigenvalue higher than 1 . While the overall variance explained in the non-gamified dataset was $77.5 \%$, the variance explained in the gamified dataset was $81.3 \%$.

As stated in Table 5, among the four categories of questions asked as per the IMMS scale, the attention category of questions scored the highest $(M=4.6)$, showing that game was considered by gamified-flipped classroom cohort students as an effective approach to improve the attention and interest in the IT. The game motivated students' attention and curiosity, and that the embedded IT business-related issues presented in the game interested students and were worthy of attention. The relevance category received a score of $(M=4.5)$, indicating that gamified flipped classroom cohort recognized the CrossQuestion game as a useful medium to learn about various IT function concepts, and it is capable to increase their sense of achievement.

The questions presented within the game also highlighted the relevant nature of such questions, and students considered the game as both entertaining and practical.

Regarding the satisfaction category $(M=4.4)$, the results indicate that the gamified-flipped classroom cohort was satisfied with the CrossQuestion game as a method of learning about the different aspects of IT in businesses. For the confidence category $(M=4.2)$, the results show that students clearly understood the rules defined for the CrossQuestion game and post preparation of material used during the in-classroom activities. Such finding highlights the significance of clearly explaining the rules of the game before using it in-class activities. Overall. the average score of over 4 (from a 5-point Likert scale) in all four categories indicated that gamified flipped classroom cohort had a strong motivation to use the CrossQuestion game to learn about the IT fundamentals.

After verifying the internal consistency and the ranking of the average scores of each category of questions, we also performed the test of normality by the Shapiro-Wilk $W$ test for the two cohorts. The results indicate that both groups are normally distributed with a statistic of 0.975 and p-value of 0.601 for the non-gamified cohort group and a statistic of 0.953 and $p$-value of 0.125 gamified-flipped cohort group. According to the normality tests, it was confirmed the validity of conducting an unpaired two-tailed t-test. The t-test results demonstrate that there was a significant difference in the motivation scores for gamified-flipped classroom cohort students $(M=3.97, S D=0.28)$ and non-gamified cohort student $(M=2.73, S D=0.37) ; t(77)=16.52, p$ value $<0.0001$. Such a result indicates that the motivation level of gamified-flipped cohort students was significantly higher than non-gamified cohort students.

\section{DISCUSSION}

Barata et al. (2013) in their research have tried to assess how gamification can impact the students learning experience by comparing gamified course to its non-gamified version from the previous year. However, they couldn't able to establish any correlation between gamification and student grades. It was suggested that grades do not best measure learning, however, it is commonly accepted as a proxy measure (Handelsman et al., 2005). Using H1, we compared the students' final grades of Spring 2019-20 (non-gamified cohort/preCOVID-19 face to face environment) and Spring 2020-21 (gamified flipped classroom cohort/during COVID19 online environment). We confirmed through the unpaired two-tailed t-test that the average final score of students in Spring 2020-21 was 11.70 points higher than students of Spring 2019-20. Although this implies the positive influence and effectiveness of CrossQuestion gamified flipped classroom experience but the improvement in final grades cannot truly represent the development of skills and knowledge that might have really occurred (Dias, 2017). We have discovered through the cross-validation that the learning effectiveness (the final grades) is significantly related to the four aspects of the ARCS model (confidence, attention, relevance, and satisfaction). Students in the Spring 2020-21 cohort during their gamified flipped classroom experience through the CrossQuestion became very competitive to win every activity session and therefore worked harder in identifying the challenging questions from the assigned course material while keeping in mind that their identified question(s) might get canceled (during the surprise stage). This resulted in more 
Table 5. IMMS-based questionnaire for the two groups

\begin{tabular}{|c|c|c|c|c|c|}
\hline \multirow{2}{*}{ Factor } & \multirow{2}{*}{ Code } & \multicolumn{2}{|c|}{ Non-gamified class $(\mathrm{N}=35)$} & \multicolumn{2}{|c|}{ Gamified flipped classroom $(\mathrm{N}=44)$} \\
\hline & & Mean & SD & Mean & SD \\
\hline \multirow[t]{10}{*}{ Confidence } & CONF1 & 2.9 & 1.1 & 4.4 & 0.49 \\
\hline & CONF2 & 2.5 & 0.18 & 4.5 & 0.66 \\
\hline & CONF3 & 3.5 & 0.98 & 4.1 & 0.55 \\
\hline & CONF4 & 2.9 & 1.2 & 4.2 & 0.5 \\
\hline & CONF5 & 3.4 & 0.94 & 4.0 & 0.69 \\
\hline & CONF6 & 2.8 & 1.1 & 4.1 & 0.62 \\
\hline & CONF7 & 3.5 & 1 & 4.3 & 0.54 \\
\hline & CONF8 & 2.8 & 1.2 & 4.2 & 0.73 \\
\hline & CONF9 & 3.6 & 1 & 4.3 & 0.81 \\
\hline & Average of CONF & 3.1 & & 4.2 & \\
\hline \multirow[t]{13}{*}{ Attention } & ATTEN1 & 3.3 & 0.94 & 4.5 & 0.63 \\
\hline & ATTEN2 & 3.2 & 0.9 & 4.7 & 0.77 \\
\hline & ATTEN3 & 3.3 & 1 & 4.4 & 0.81 \\
\hline & ATTEN4 & 2.4 & 1.1 & 4.6 & 0.62 \\
\hline & ATTEN5 & 2.3 & 1.1 & 4.5 & 0.63 \\
\hline & ATTEN6 & 3.5 & 1 & 4.5 & 0.5 \\
\hline & ATTEN7 & 3.1 & 0.95 & 4.6 & 0.62 \\
\hline & ATTEN8 & 3 & 0 & 4.4 & 0.63 \\
\hline & ATTEN9 & 3 & 0.93 & 4.5 & 0.59 \\
\hline & ATTEN10 & 3.4 & 0.97 & 4.7 & 0.58 \\
\hline & ATTEN11 & 2.1 & 1.1 & 4.8 & 0.54 \\
\hline & ATTEN12 & 2.7 & 1.2 & 4.9 & 0.55 \\
\hline & Average of ATTEN & 2.9 & & 4.6 & \\
\hline \multirow[t]{10}{*}{ Relevance } & RELE1 & 3.3 & 0.98 & 4.5 & 0.7 \\
\hline & RELE2 & 3.5 & 1.2 & 4.6 & 0.55 \\
\hline & RELE3 & 3.1 & 1.2 & 4.6 & 0.66 \\
\hline & RELE4 & 3.2 & 1 & 4.6 & 0.55 \\
\hline & RELE5 & 3.4 & 0.8 & 4.4 & 0.59 \\
\hline & RELE6 & 3.3 & 1 & 4.6 & 0.57 \\
\hline & RELE7 & 2 & 0.87 & 4.7 & 0.47 \\
\hline & RELE8 & 3.4 & 1.1 & 4.5 & 0.59 \\
\hline & RELE9 & 3.6 & 1.2 & 4.5 & 0.73 \\
\hline & Average of RELE & 3.2 & & 4.5 & \\
\hline \multirow[t]{9}{*}{ Satisfaction } & SAT1 & 3.2 & 1.1 & 4.4 & 0.58 \\
\hline & SAT2 & 3.3 & 0.92 & 4.5 & 0.69 \\
\hline & SAT3 & 2.9 & 1.4 & 4.6 & 0.55 \\
\hline & SAT4 & 3.2 & 1.2 & 4.3 & 0.63 \\
\hline & SAT5 & 3.6 & 1.1 & 4.2 & 0.66 \\
\hline & SAT6 & 3.3 & 1.1 & 4.5 & 0.63 \\
\hline & Average of SAT & 3.25 & & 4.4 & \\
\hline & Overall average & 3.1 & & 4.45 & \\
\hline & Cronbach's alpha & 0.86 & & 0.92 & \\
\hline
\end{tabular}

attention given by the students, which boosted their overall confidence and understanding of the IT concepts. They also felt a greater sense of satisfaction during the CrossQuestion game process, which ultimately resulted in increasing the learning effectiveness. The result in this study is significantly different from the outcome of Kwon and Ozpolat (2021). In their study they found that gamifying assessment activities results in significantly lower content knowledge, satisfaction, and course experience. In addition, team exam scores were significantly lower in the gamified group as compared to individual exam scores in other assessments.

For the $\mathbf{H 2}$, we used the IMMS scale to measure motivation through attention, relevance, confidence, and satisfaction. Also, one open-ended question was included in the survey to gather information about their overall experience with the course. Based on the results presented in Table 5, gamified flipped classroom 
cohort has shown more confidence, attention to detail, understanding of the relevance of the content of the courses to their functional areas, and overall satisfaction with the course delivery. Our result is consistent with the study of Rincon-Flores and Santos-Guevara (2021), where they reported the results of two gamified undergraduate courses designed with a reward system. They concluded that gamification favors the relationship between attention, participation, and performance, while promoting the humanization of virtual environments. A comment given by one of our student from the Spring 2020-21 cohort described how gamified flipped classroom experience through CrossQuestion has enhanced her attention "... I liked...the course... (because) ... in-class activities made the course much more fun and enabled us to learn interactively...". Another student highlighted the role of gamified experience through CrossQuestion to improve his understanding of IT and how it connected with their functional areas "... I found the ... class activities very useful and fun. It helped (me) to familiarize (with the IT) concepts and how it is related to my (functional) area...I liked the gamified flipped classroom activities...". However, there are also some concerns that were raised by the students. As an example, "... the classroom activities...was not done in a specific group, which means that some will... do [all] the work while others won't...so that made some student dislike the in-classroom activity...". A finance student from gamified flipped classroom cohort stated "...as a finance student, this course demanded a lot of memorizing which was my least favorite part. However, I found the Tuesday class activities very useful and fun. It helped us to familiarize ourselves with the [IT] concepts and made it fun. I liked the gamified flipped classroom activities....". As a statement about teamwork "...as a nonIT student, I learned new things about information technology and the way [it was taught] to us was amazing [. I] enjoyed the games during the class and the team works..."

\section{CONCLUSIONS, IMPLICATIONS, AND LIMITATIONS}

The year 2020 brought us multi-facet challenges due to COVID-19. These challenges impacted us emotionally, psychologically, technologically, and physically. For us, a bigger challenge was the delivery of technical courses to students with a non-technical background in a digital synchronous environment. We proposed a gamification-flipped classroom approach to deliver such courses through our application the "CrossQuestion". We aimed to engage students through a competitive group-oriented assessment environment.

Our contribution is a case study to the emerging body of literature on the ARCS model, processes, and practices and its application through custom-designed educational games. We have demonstrated through CrossQuestion how to engage students with no background on the subject using gamification and flipped classroom practices in alignment with the ARCS model. The overall result of using our CrossQuestion game has shown a strong learning motivation by the gamified flipped classroom cohort. It also implies that our game has the elements of practicality and entertainment to successfully establish the relevance of the course content with the gamified flipped classroom cohort. This relevance as a result has stimulated the attention and interest of the students to gain useful IT knowledge which might apply to their functional areas and getting a high level of satisfaction.

This study has implications for instructors, academics, instructional designers, educational game designers/developers, and researchers. From instructors, academics, and researcher perspectives, we have demonstrated the integration of ARCS model practices and its application through our CrossQuestion game to enhance or sustain student motivation and learning effectiveness. The competitive environment of the game enables the instructors to get students' attention easily, where students willingly opt to prepare for particular concepts in a group, resulting in a better understanding of topics and their relevance to their functional areas. This as a result boost students' confidence in the overall course to acquire intrinsic and extrinsic satisfaction. Researchers, instructors, and academics can apply our game in a different course context to test the learning effectiveness and students' motivation. Instructional designers and educators can follow our experience to develop or customized their courses so that they can be plugged in with the CrossQuestion game for better integration. Educational game designers/developers can learn from our game development experience to apply the ARCS model, its proposed processes, and practices in their educational context to develop more motivational games for the students. 
There are limitations and challenges that we need to consider and continuously improve our CrossQuestion game for a consistent learning experience for the students. This includes tracking individual contributions in a group-based environment. Our game has used the functionality of the Zoom communication tool to enable the live video, voice, and text chat between teams and the teacher. In our future development of this game, we will integrate this feature as part of the game environment to further improve interactivity and engagement. Currently, one responsibility of a teacher is to navigate the students through various stages of the game. We are now planning to improve this student experience by providing a mobile interface for the students to respond to the questions and the system to automatically navigate teams to the next stages. For this study, we have applied gamified flipped classroom approach using the CrossQuestion game to the online cohort and the non-gamified cohort was delivered courses using face-to-face lectures with paper-based assessments. So, the significant improvements as noted in this study cannot be generalized unless more studies are performed using this same approach in a face to face and online environments. Also, this game was applied to one course only and the result cannot be generalized unless it is applied to multiple other courses. Our future studies will use the enhanced version of the CrossQuestion application using gamified and flipped classroom pedagogies in other academic programs such as medical, architecture, engineering, and professional training.

Author contributions: All authors were involved in concept, design, collection of data, interpretation, writing, and critically revising the article. All authors approve final version of the article.

Funding: The study was supported by a grant from the United Arab Emirates University (UAEU), Fund Number: 31 B121.

Declaration of interest: Authors declare no competing interest.

Data availability: Data generated or analysed during this study are available from the authors on request.

\section{REFERENCES}

Al-Adwan, A. S., Albelbisi, N. A., Hujran, O., Al-Rahmi, W. M., \& Alkhalifah, A. (2021). Developing a holistic success model for sustainable e-learning: A structural equation modeling approach. Sustainability, 13(16), 9453. https://doi.org/10.3390/su13169453

Asiksoy, G. (2017). The effects of the gamified flipped classroom environment (GFCE) on students' motivation, learning achievements, and perception in a physics course. Quality \& Quantity, 52(S1), 129-145. https://doi.org/10.1007/s11135-017-0597-1

Barata, G., Gama, S., Jorge, J., \& Gonçalves, D. (2013). Engaging engineering students with gamification. In IEEE 2013 5th International Conference on Games and Virtual Worlds for Serious Applications (pp. 18). https://doi.org/10.1109/VS-GAMES.2013.6624228

Bishop, J., \& Verleger, M. A. (2013). The flipped classroom: A survey of the research [Paper presentation]. 2013 ASEE Annual Conference Exposition, Atlanta, Georgia. https://doi.org/10.18260/1-2--22585

Chyung, S. Y. (2001). Systematic and systemic approaches to reducing attrition rates in online higher education. American Journal of Distance Education, 15(3), 36-49. https://doi.org/10.1080/ 08923640109527092

Clarke, S., \& Blissenden, M. (2013). Assessing student group work: Is there a right way to do it? The Law Teacher, 47(3), 368-381. https://doi.org/10.1080/03069400.2013.851340

Deterding, S., Dixon, D., Khaled, R., \& Nacke, L. (2011). From game design elements to gamefulness: Defining "gamification". In Proceedings of the 15th International Academic MindTrek Conference: Envisioning Future Media Environments (pp. 9-15). Tampere, Finland. https://doi.org/10.1145/2181037.2181040

Dias, J. (2017). Teaching operations research to undergraduate management students: The role of gamification. The International Journal of Management Education, 15(1), 98-111. https://doi.org/ 10.1016/j.ijme.2017.01.002 
Durrani, U., Alnajjar, R., Al Muaitah, A., Daqaq, A., Salah, A., \& Zeyad, R. (2021). CrossQuestion game: A design of a group-based assessment tool to enhance student motivation during pandemic. International Journal of Information and Education Technology. https://doi.org/10.18178/ijiet.2022.12.1.1581

Gamlath, S., \& Wilson, T. (2017). Knowledge sharing among university students: A review of current practices. SSRN. https://doi.org/10.2139/ssrn.2962616

Goh, C. F., \& Ong, E. T. (2019). Flipped classroom as an effective approach in enhancing student learning of a pharmacy course with a historically low student pass rate. Currents in Pharmacy Teaching and Learning, 11(6), 621-629. https://doi.org/10.1016/j.cptl.2019.02.025

Green, M., \& Sulbaran, T. (2006). Motivation assessment instrument for virtual reality scheduling simulator. In T. Reeves, \& S. Yamashita (Eds.), Proceedings of E-Learn 2006--World Conference on E-Learning in Corporate, Government, Healthcare, and Higher Education (pp. 45-50). Association for the Advancement of Computing in Education.

Hammar Chiriac, E. (2014). Group work as an incentive for learning-students' experiences of group work. Frontiers in Psychology, 5, 558. https://doi.org/10.3389/fpsyg.2014.00558

Handelsman, M. M., Briggs, W. L., Sullivan, N., \& Towler, A. (2005). A measure of college student course engagement. The Journal of Educational Research, 98, 184-192. https://doi.org/10.3200/ JOER.98.3.184-192

Healy, M., Doran, J., \& McCutcheon, M. (2018). Cooperative learning outcomes from cumulative experiences of group work: Differences in student perceptions. Accounting Education, 27(3), 286-308. https://doi.org/10.1080/09639284.2018.1476893

Heathfield, M. (1999). Group-based assessment: An evaluation of the use of assessed tasks as a method of fostering higher quality learning. Assessment Matters in Higher Education, 132-145.

Hwang, G. J., Chiu, L. Y., \& Chen, C. H. (2015). A contextual game-based learning approach to improving students' inquiry-based learning performance in social studies courses. Computers \& Education, 81, 13-25. https://doi.org/10.1016/j.compedu.2014.09.006

Jang, J., Park, J. J., \& Mun, Y. Y. (2015). Gamification of online learning. In: C. Conati, N. Heffernan, A. Mitrovic, \& M. F. Verdejo (Eds.), Artificial intelligence in education (pp. 646-649). Springer. https://doi.org/ 10.1007/978-3-319-19773-9_82

Jensen, J. L., Holt, E. A., Sowards, J. B., Ogden, T. H., \& West, R. E. (2018). Investigating strategies for pre-class content learning in a flipped classroom. Journal of Science Education and Technology, 27(6), 523-535. https://doi.org/10.1007/s10956-018-9740-6

Jo, J., Jun, H., \& Lim, H. (2018). A comparative study on gamification of the flipped classroom in engineering education to enhance the effects of learning. Computer Applications in Engineering Education, 26(5), 1626-1640. https://doi.org/10.1002/cae.21992

Joo, M. H. (2017). Students' group work contribution: Influence of work preference, gender, and individual assessment. Social Behavior and Personality: An International Journal, 45(1), 19-28. https://doi.org/ $10.2224 /$ sbp. 5385

Juan, Y. K., \& Chao, T. W. (2015). Game-based learning for green building education. Sustainability, 7(5), 55925608. https://doi.org/10.3390/su7055592

Kaufmann, D. A. (2018). Reflection: Benefits of gamification in online higher education. Journal of Instructional Research, 7, 125-132. https://doi.org/10.9743/JIR.2018.12

Keller, J. M. (2010). Motivational design for learning and performance: The ARCS model approach. Springer. https://doi.org/10.1007/978-1-4419-1250-3 
Krause, M., Mogalle, M., Pohl, H., \& Williams, J. J. (2015). A playful game-changer: Fostering student retention in online education with social gamification. In Proceedings of ACM Conference on Learning (pp. 95102). Canada. https://doi.org/10.1145/2724660.2724665

Kwon, H. Y., \& Ozpolat, K. (2021). The dark side of narrow gamification: Negative impact of assessment gamification on student perceptions and content knowledge. INFORMS Transactions on Education, 21(2), 67-81. https://doi.org/10.1287/ited.2019.0227

Li, K., \& Keller, J. M. (2018). Use of the ARCS model in education: A literature review. Computers \& Education, 122, 54-62. https://doi.org/10.1016/j.compedu.2018.03.019

Lo, C. K., \& Hew, K. F. (2020). A comparison of flipped learning with gamification, traditional learning, and online independent study: The effects on students' mathematics achievement and cognitive engagement. Interactive Learning Environments, 28(4), 464-481. https://doi.org/10.1080/ 10494820.2018.1541910

Loorbach, N., Peters, O., Karreman, J., \& Steehouder, M. (2015). Validation of the Instructional materials motivation survey (IMMS) in a self-directed instructional setting aimed at working with technology. British Journal of Educational Technology, 46(1), 204-218. https://doi.org/10.1111/bjet.12138

Malik, S. (2014). Effectiveness of ARCS model of motivational design to overcome the non-completion rate of students in distance education. Turkish Online Journal of Distance Education, 15(2), 194-200. https://doi.org/10.17718/tojde.18099

Mbalamula, Y. (2018). Effect of group versus individual assessments on coursework among undergraduates in Tanzania: Implications for continuous assessments in universities. Pedagogical Research, 3(1) https://doi.org/10.20897/pr/85171

McCarthy, J. (2016). Reflections on a flipped classroom in first-year higher education. Issues in Educational Research, 26(2), 332-350. http://www.iier.org.au/iier26/mccarthy-j.html

McLaughlin, J. E., Roth, M. T., Glatt, D. M., Gharkholonarehe, N., Davidson, C. A., Griffin, L. M., Esserman, D. A., \& Mumper, R. J. (2014). The flipped classroom: A course redesign to foster learning and engagement in a health professions school. Academic Medicine, 89(2), 236-243. https://doi.org/ $10.1097 / \mathrm{acm} .0000000000000086$

McLaughlin, J. E., White, P. J., Khanova, J., \& Yuriev, E. (2016). Flipped classroom implementation: A case report of two higher education institutions in the United States and Australia. Computers in the Schools, 33(1), 24-37. https://doi.org/10.1080/07380569.2016.1137734

Milman, N. B. (2012). The flipped classroom strategy: What is it and how can it best be used? Distance Learning, 9(3), 85-87.

Milman, N. B., \& Wessmiller, J. (2016). Motivating the online learner using Keller's ARCS model. Distance Learning, 13(2), 67.

Nouri, J. (2016). The flipped classroom: For active, effective, and increased learning-especially for low achievers. International Journal of Educational Technology in Higher Education, 13(1). https://doi.org/10.1186/s41239-016-0032-z

Pavlíková, M., Sirotkin, A., Králik, R., Petrikovičová, L., \& Martin, J. G. (2021). How to keep university active during COVID-19 pandemic: Experience from Slovakia. Sustainability, 13(18), 10350. https://doi.org/ $10.3390 /$ su131810350

Rincon-Flores, E. G., \& Santos-Guevara, B. N. (2021). Gamification during COVID-19: Promoting active learning and motivation in higher education. Australasian Journal of Educational Technology, 37(5), 43-60. https://doi.org/10.14742/ajet.7157 
Rodgers, D. L., \& Withrow-Thorton, B. J. (2005). The effect of instructional media on learner motivation. International Journal of Instructional Media, 32(4), 333.

Safapour, E., Kermanshachi, S., \& Taneja, P. (2019). A review of nontraditional teaching methods: Flipped classroom, gamification, case study, self-learning, and social media. Education Sciences, 9(4), 273. https://doi.org/10.3390/educsci9040273

Sailer, M., \& Sailer, M. (2021). Gamification of in-class activities in flipped classroom lectures. British Journal of Educational Technology, 52(1), 75-90. https://doi.org/10.1111/bjet.12948

Simões, J., Redondo, R. D., \& Vilas, A. F. (2013). A social gamification framework for a K-6 learning platform. Computers in Human Behavior, 29(2), 345-353. https://doi.org/10.1016/j.chb.2012.06.007

Subhash, S., \& Cudney, E. A. (2018). Gamified learning in higher education: A systematic review of the literature. Computers in Human Behavior, 87, 192-206. https://doi.org/10.1016/j.chb.2018.05.028

Tkáčová, H., Pavlíková, M., Jenisová, Z., Maturkanič, P., \& Králik, R. (2021). Social media and students' wellbeing: An empirical analysis during the COVID-19 pandemic. Sustainability, 13(18), 10442. https://doi.org/10.3390/su131810442

Yildirim, I. (2017). The effects of gamification-based teaching practices on student achievement and students' attitudes toward lessons. The Internet and Higher Education, 33, 86-92. https://doi.org/10.1016/ j.iheduc.2017.02.002

Zainuddin, Z. (2018). Students' learning performance and perceived motivation in gamified flipped-class instruction. Computers \& Education, 126, 75-88. https://doi.org/10.1016/j.compedu.2018.07.003

Correspondence: Omar Hujran, Department of Analytics in the Digital Era, College of Business and Economics, United Arab Emirates University, United Arab Emirates. E-mail: o.hujran@uaeu.ac.ae 